\title{
Integrated Millimeter-Wave Antennas for On-Chip Communication
}

\author{
Saber H. Zainud-Deen ${ }^{1}$, Saied Abd Elhamied ${ }^{2}$, and Hend A. Malhat ${ }^{3}$ \\ Faculty of Electronic Eng., Menoufia University, Egypt \\ 1anssaber@yahoo.com, ${ }^{2}$ s_abdelhamied@yahoo.com \\ ${ }^{3}$ corresponding author, E-mail: er_honidal@yahoo.com
}

\begin{abstract}
This paper introduces the design and analysis of circularly polarized (CP) and dual-polarized on-chip microstrip antennas for wireless communication at $60 \mathrm{GHz}$. The $\mathrm{CP}$ on-chip antenna consists of a circular aluminum patch with two overlapped circular slots fed by the transmission line. The radiation characteristics of the $\mathrm{CP}$ have been analyzed using the finite integration technique and finite element method based electromagnetic solvers. The CP antenna introduces left-hand circular polarization and employs as on-chip transmitter. A design of dual-polarized on-chip microstrip antenna at $60 \mathrm{GHz}$ is investigated and is employed as on-chip receiver. The dual ports of the dual polarized antenna are designed with high isolation between them in order to be used as a two on-chip receivers. The radiation characteristics of the dual-port antenna have been calculated. The effect of the separation distance between the $\mathrm{CP}$-antenna and the dual-polarized antenna on the same chip has been investigated. The performance parameters like the reflection coefficient, transmission coefficient, and the transmission gain of the two antennas at different separation distances have been introduced.
\end{abstract}

\section{Introduction}

Recently, there is a special interest in the short range communication applications in the $60-\mathrm{GHz}$ band [1]. A variety of applications such as uncompressed high definition video streaming, mobile distributed computing, wireless gaming, internet access, and wireless personal area networks falls into the $60 \mathrm{GHz}$ band communications interest [2]. This frequency band is characterized by high attenuation of atmospheric oxygen of $10-15 \mathrm{~dB} / \mathrm{km}$ in a bandwidth of about $7 \mathrm{GHz}$ centered at $60 \mathrm{GHz}$ [3]. A multiGbps wireless connectivity can be realized for short distances between electronic devices for this communication [4]. The data rate increases to 40-100 times faster than current technologies. Integration of the antennaon-chip with different communication circuits introduces low fabrication cost due to the elimination of cost associated with materials required for off-chip (external) antennas [5]. Moreover, the antenna matching circuits will be eliminated as the $50 \mathrm{Ohm}$ boundary is no longer needed.
The antenna integration, on-chip allows one step fabrication for the solid wireless system.

Complementary metal-oxide semiconductor (CMOS) is an effective technology because its high-frequency performance has been improved through scaling [6]. A typical $0.18 \mu \mathrm{m}$ CMOS-technology consists of 6-8 metal layers embedded in silicon oxide layers is introduced in [7]. The top metal layer is utilized to fabricate the on-chip antennas, while the bottom metal layer is applied as a ground shield for reducing the losses [6]. However, the CMOS substrate is characterized by low resistivity and high permittivity; hence, antenna on-chip performance is poor in terms of gain, radiation efficiency and front-to-back ratio (FBR). Different antennas have been integrated in CMOS systems such as dipoles, dielectric resonator antennas, and microstrip antennas in the literature [8-10]. The antenna radiation characteristics are improved by using on-chip ground where the bottom metal layer is used as a ground shield for reducing the losses from low resistivity silicon substrate. An on-chip antenna has also been employed as a transformer in radio frequency identification systems (RFIDs) [11]. A single chip transceiver with on-chip antennas can provide a wireless communication link for sensor network. On-chip antennas can be employed for wireless data communication between different chips to minimize the pin counts, reducing the form factor, packaging costs, and signal delays [12]. Two-dipole pairs have been investigated for chip to chip communication in [13]. Circularly polarized (CP) antennas are desirable in wireless communication to minimize the path loss between the transmitter and receiver antennas and freedom of their orientation. A $60 \mathrm{GHz}$ artificial magnetic conductor based $\mathrm{CP}$ on-chip antenna has been designed and fabricated using standard $0.18 \mu \mathrm{m}$ six metal-layer CMOS technology in [14].

In this paper, the connection between $\mathrm{CP}$ on-chip antenna and dual-polarized on-chip antenna integrated for a $60-\mathrm{GHz}$ CMOS single-chip transceiver is designed and analyzed. The radiation characteristics of on-chip antennas are investigated. The CP on-chip antenna is used as a transmitter, while dual-polarized on-chip antenna with dual feed transmission lines is used as a receiver for two 
different circuits on the same chip. The effect of the separation distance between the CP- and dual-polarized onchip antennas on the radiation characteristics of the two antennas have been investigated. The HFSS finite element method (FEM) [15] and the CST Microwave studio finite integration technique (FIT) [16] -based on 3-D full-wave electromagnetic solvers are used for the simulation in this paper.

\section{Numerical results}

\subsection{Circularly-polarized circular microstrip on-chip patch antenna}

A schematic of the proposed CMOS on-chip CP-microstrip antenna is shown in Fig.1a. The antenna consists of circular patch printed on the CMOS substrate six-layer structure. The circular microstrip antenna dimensions are designed for dominant mode TM11 at $60 \mathrm{GHz}$ applications. The resonance frequency is given by [17]

$$
f_{11}=\frac{c}{2 \pi R_{e} \sqrt{\varepsilon_{r e}}} x_{11}^{\prime} \quad \text { where } x_{11}^{\prime}=1.842
$$

where $R_{e}$ is the effective patch radius due to the fringing effect, and $\varepsilon_{\mathrm{re}}$ is the effective relative dielectric constant of the substrate. A fine tuning for the patch dimensions is used to adjust the resonance frequency. The circular patch is made from aluminium with thickness $1 \mu \mathrm{m}$, radius $\mathrm{R}=0.68$ $\mathrm{mm}$ and two overlapped identical circular slots with radius $\mathrm{R}_{\mathrm{s}}=0.115 \mathrm{~mm}$ and center to center separation $\mathrm{C}=74 \mu \mathrm{m}$ are cut out from the patch. A microstrip transmission line is used for feeding the patch. The transmission line consists of two sections for impedance transformation and has dimensions $\mathrm{L}_{\mathrm{t}}=0.2 \mathrm{~mm}, \mathrm{~L}_{\mathrm{f}}=0.435 \mathrm{~mm}, \mathrm{w}_{\mathrm{t}}=10 \mu \mathrm{m}$ and $\mathrm{w}_{\mathrm{f}}=30$ $\mu \mathrm{m}$. The microstrip patch antenna and the transmission line are on the top metal layer in the CMOS structure. A silicon oxide substrate with $\varepsilon_{\mathrm{r}}=4$, length $\mathrm{L}_{\mathrm{s}}=2.4 \mathrm{~mm}$, width $\mathrm{w}_{\mathrm{s}}=2.2$ $\mathrm{mm}$, and thickness $\mathrm{h}_{\mathrm{d}}$ of $22 \mu \mathrm{m}$ is placed under the circular patch. The first metal layer in the CMOS structure is used as on-chip ground under the silicon oxide layer. The silicon chip substrate with $\varepsilon_{\mathrm{r}}=11.9$ and $\sigma=10 \mathrm{~S} / \mathrm{m}$ and thickness $\mathrm{h}_{\mathrm{s}}$ of $300 \mu \mathrm{m}$ is placed beneath the ground plane.

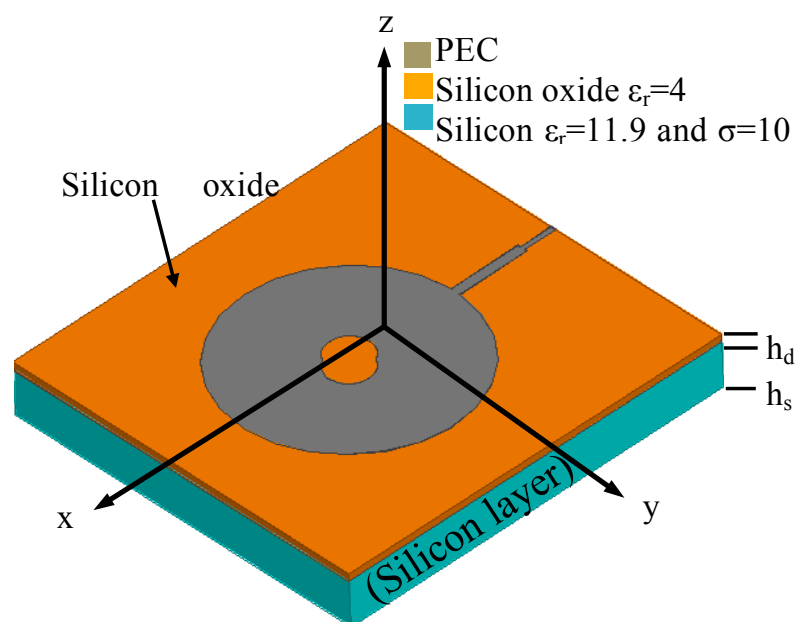

a. 3-D view

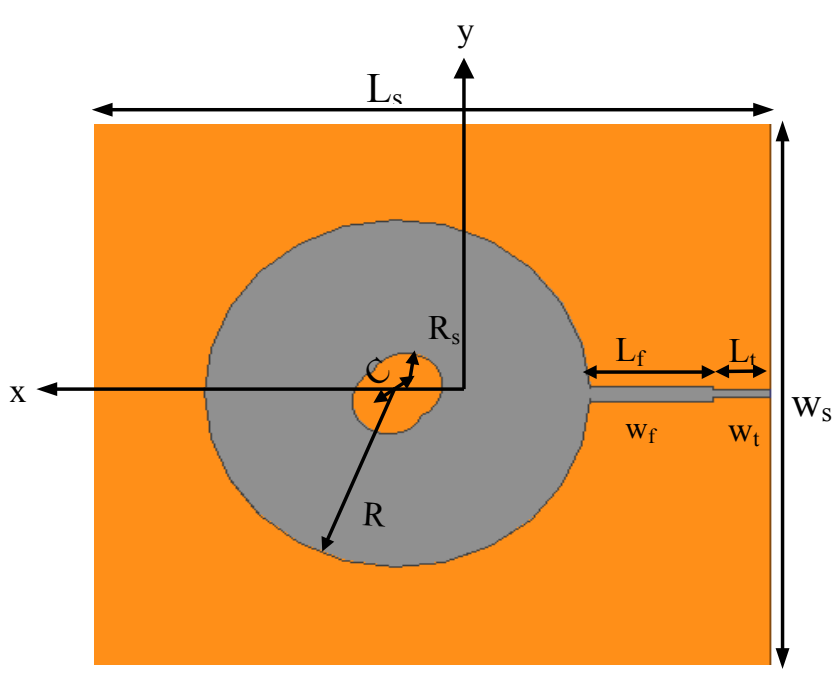

b. Top view

Fig.1. The configuration of the $\mathrm{CP}$ microstrip on-chip patch antenna with $\mathrm{L}_{\mathrm{s}}=2.4 \mathrm{~mm}, \mathrm{~W}_{\mathrm{s}}=2.2 \mathrm{~mm}, \mathrm{~h}_{\mathrm{s}}=300 \mu \mathrm{m}$, $\mathrm{h}_{\mathrm{d}}=22 \mu \mathrm{m}, \mathrm{R}=0.6825 \mathrm{~mm}, \mathrm{R}_{\mathrm{s}}=0.115 \mathrm{~mm}, \mathrm{~L}_{\mathrm{f}}=0.435 \mu \mathrm{mm}$, $\mathrm{L}_{\mathrm{t}}=0.2 \mathrm{~mm}, \mathrm{w}_{\mathrm{f}}=30 \mu \mathrm{m}, \mathrm{w}_{\mathrm{t}}=10 \mu \mathrm{m}$, and $\mathrm{C}=74 \mu \mathrm{m}$.

The variation of the reflection coefficient versus frequency for the CP on-chip antenna is shown in Fig. 2a. The antenna structure is simulated using the FIT and its results are compared with that obtained using the FEM. Good agreement between results is obtained. The antenna introduces impedance matching bandwidth of $2.85 \mathrm{GHz}$. The surface current distribution on the CP-microstrip antenna is shown in Fig. 2b. The surface current has its maximum amplitude around the feeding transmission line and around the circular slots. The two overlapped circular slots exhibit an electrically asymmetrical structure which induces two modes $\left(\mathrm{TM}_{10}\right.$, and $\left.\mathrm{TM}_{01}\right)$ that have equal amplitudes and a $90^{\circ}$ phase difference. The current flows in the clockwise direction results in left-handed circular polarization mode. The variations of antenna gain and radiation efficiency versus frequency for the $\mathrm{CP}$-antenna are shown in Fig. 3a. A maximum gain of $0.3 \mathrm{dBi}$ at $60 \mathrm{GHz}$ is obtained with variation within $1.4 \mathrm{~dB}$ over the entire frequency band $(55-65 \mathrm{GHz})$. The radiation efficiency of the antenna is within $25 \%$ at $60 \mathrm{GHz}$. The variation of the radiation efficiency versus the silicon oxide thickness is shown in Fig. 3b. As the silicon oxide layer thickness is increased, the radiation efficiency is increased. The axial ratio variation versus frequency at the broadside direction is shown in Fig. 3c. Again, good agreement between the FEM and FIT results is depicted. The antenna introduces circular polarization properties at $60 \mathrm{GHz}$ with an axial ratio of 1.9 $\mathrm{dB}$ and axial ratio bandwidth of $600 \mathrm{MHz}(6 \%)$. The circular polarization radiation pattern components $E_{L}$ (lefthand) and $E_{R}$ (right-hand) at $60 \mathrm{GHz}$ in $x-z$ and $y-z$ planes are shown in Fig. 4. The antenna introduces left-hand circular polarization with front-to-back ratio (FBR) of 
$26 / 27.5 \mathrm{~dB}$ in the two planes with co-/cross-polarization of $31.9 / 33.8 \mathrm{~dB}$ at $\theta=0$.

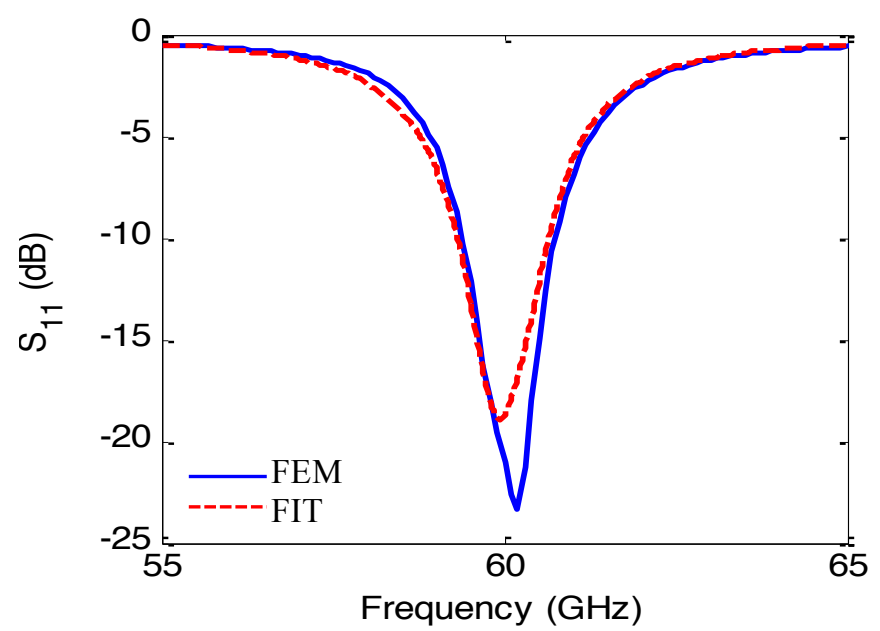

a. Return loss (dB)

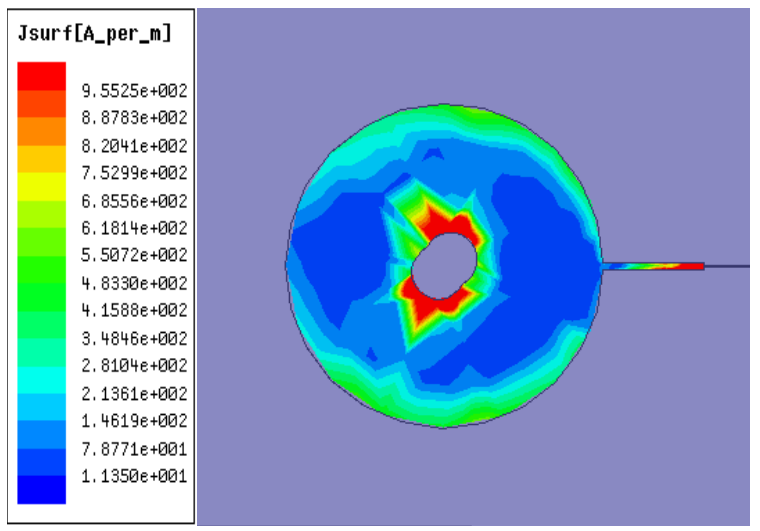

b. Surface current

Fig. 2 a. The variation of return loss versus frequency of CP microstrip patch on-chip antenna. b. The surface current distribution on the $\mathrm{CP}$ microstrip patch on-chip antenna at $60 \mathrm{GHz}$.

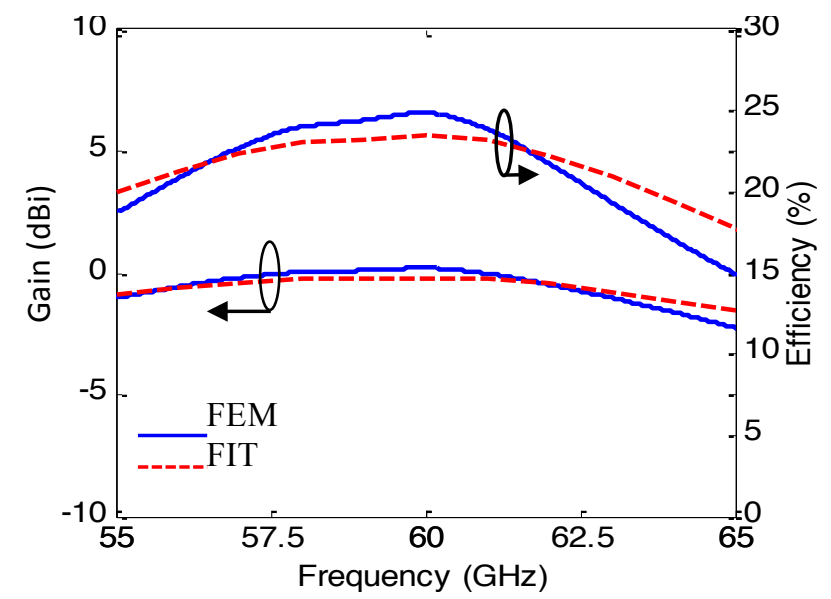

a. Gain and efficiency

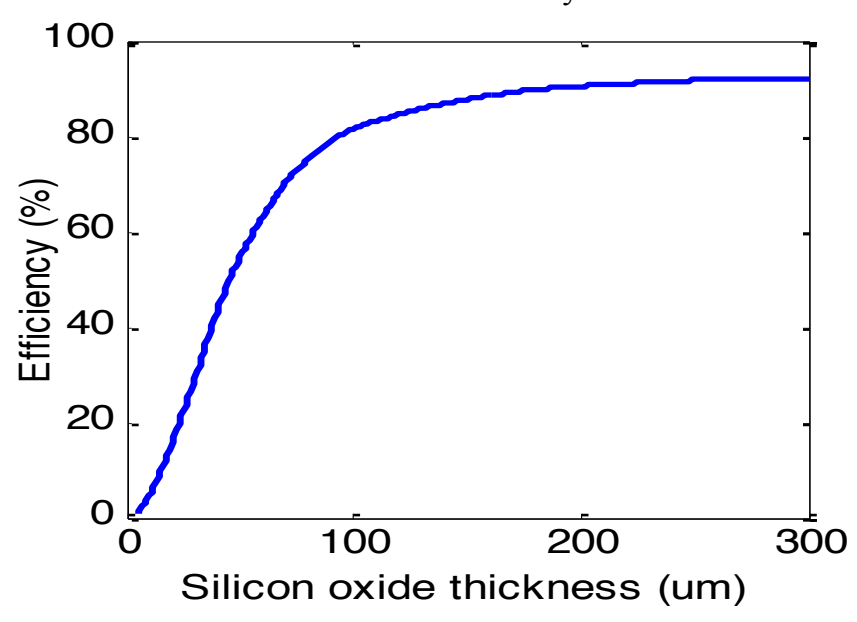

b. Radiation efficiency

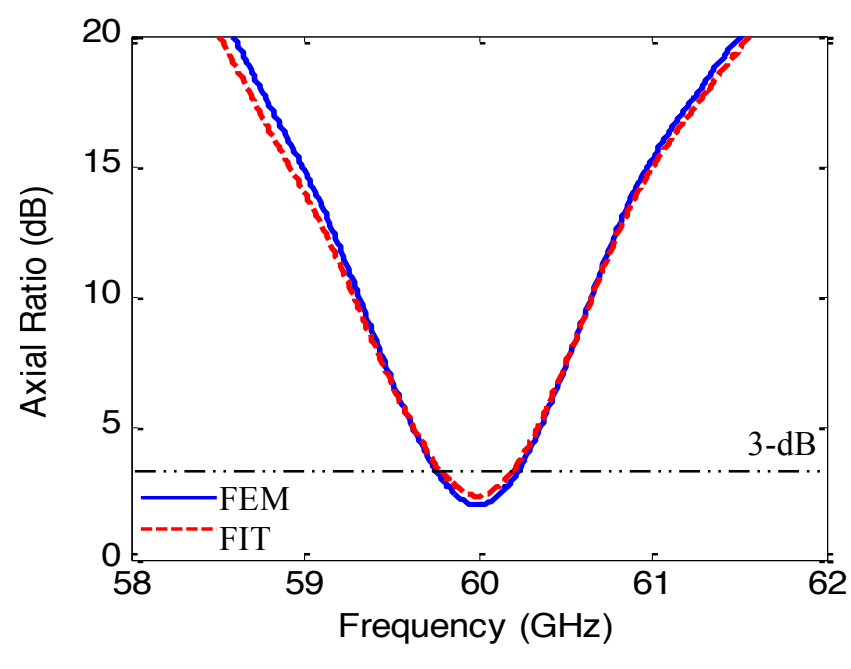

c. Axial ratio

Fig. 3 a. The variations of the gain and radiation efficiency versus frequency of CP microstrip patch on-chip antenna. $b$. The variation of the radiation efficiency versus the silicon oxide thickness. c. The variation of the axial ratio versus frequency for CP microstrip patch on-chip antenna.

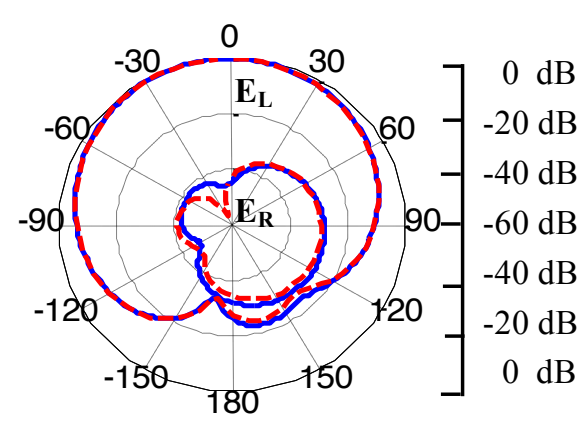

a. $y-z$ plane 


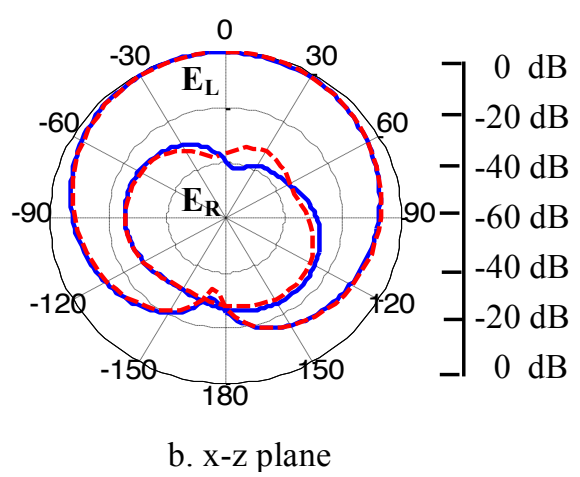

Fig. 4. The circular polarization radiation patterns of the $C P$ on-chip antenna in $\mathrm{x}-\mathrm{z}$ and $\mathrm{y}-\mathrm{z}$ planes at $60 \mathrm{GHz}$.

\subsection{Dual-polarized square microstrip patch on-chip antenna}

The geometry of the dual-polarized square microstrip patch on-chip antenna with detailed dimensions is shown in Fig. 5. The square patch is printed on a silicon oxide substrate of thickness $h_{d}=22 \mu \mathrm{m}$ with aluminium ground plane. The resonance frequency for the fundamental mode $\mathrm{TM}_{10}$ is given by [17]

$$
f_{10}=\frac{c}{2 \pi L_{p e} \sqrt{\varepsilon_{r e}}}
$$

where $\mathrm{L}_{\mathrm{pe}}$ is the effective patch length due to the fringing effect. The square patch has side-length $\mathrm{L}_{\mathrm{p}}=1.2 \mathrm{~mm}$. Two orthogonal microstrip transmission lines are used to feed the square patch for dual-polarization. Each transmission line consists of two sections for impedance transformation and has dimensions $\mathrm{L}_{\mathrm{t}}=0.2 \mathrm{~mm}, \mathrm{~L}_{\mathrm{f}}=0.435 \mathrm{~mm}, \mathrm{w}_{\mathrm{t}}=10 \mu \mathrm{m}$ and $\mathrm{w}_{\mathrm{f}}=30 \mu \mathrm{m}$. The two transmission lines are symmetrically oriented about the edge center of the square patch to excite two orthogonal modes. The same silicon oxide and silicon substrates in section A is used for dual-polarization on-chip antenna.

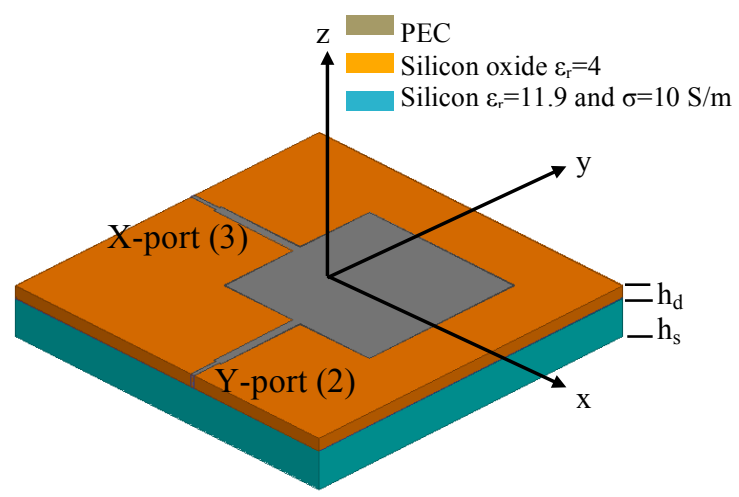

a. 3-D view

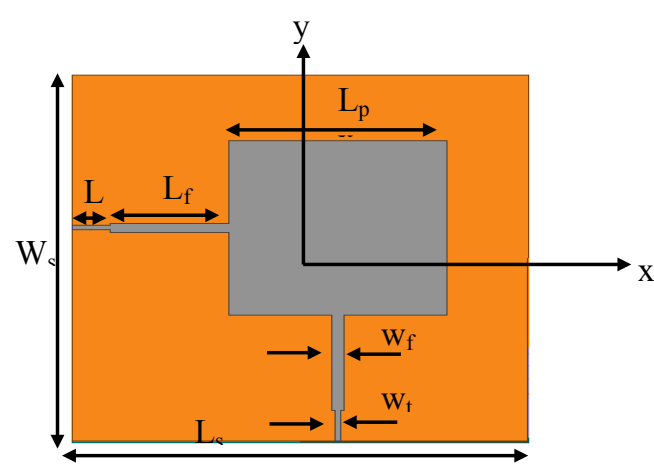

b. Top view

Fig. 5. The configuration of the dual-polarized microstrip patch on-chip antenna with $\mathrm{L}_{\mathrm{s}}=2.4 \mathrm{~mm}, \mathrm{~W}_{\mathrm{s}}=2.4 \mathrm{~mm}$, $\mathrm{h}_{\mathrm{s}}=300 \mu \mathrm{m}, \mathrm{h}_{\mathrm{d}}=22 \mu \mathrm{m}, \mathrm{L}_{\mathrm{p}}=1.2 \mathrm{~mm}, \mathrm{~L}_{\mathrm{f}}=0.435 \mathrm{~mm}, \mathrm{~L}_{\mathrm{t}}=0.2$ $\mathrm{mm}, \mathrm{w}_{\mathrm{f}}=30 \mu \mathrm{m}$, and $\mathrm{w}_{\mathrm{t}}=10 \mu \mathrm{m}$.

The variations of the reflection coefficients $\left(\mathrm{S}_{22}\right.$ and $\mathrm{S}_{33}$ ) and the isolation $\left(\mathrm{S}_{32}\right)$ for both the $\mathrm{X}$-port (in $\mathrm{X}$-axis direction) and $\mathrm{Y}$-port (in $\mathrm{y}$-axis direction) versus frequency are presented in Fig. 6a. The same reflection coefficient variation versus frequency is obtained for both the $\mathrm{X}$ - and Y- ports due to the symmetry in the patch and the transmission line position on the antenna. The resonance frequency is $60 \mathrm{GHz}$ with impedance matching bandwidth of $1.120 \mathrm{GHz}$. Good isolation between the two ports is obtained and it is close to $-25.4 \mathrm{~dB}$ at $60 \mathrm{GHz}$ and below this value over the whole frequency band. The variations of antenna gain and radiation efficiency versus frequency for the dual-ports are shown in Fig. 6b. Both the X-port and Yport introduce maximum gain of $0.7 \mathrm{dBi}$ and radiation efficiency of $25 \%$ at $60 \mathrm{GHz}$. The simulated surface current distributions on the dual- polarized microstrip patch on-chip antenna for the both the X-port and Y-port at $60 \mathrm{GHz}$ are shown in Fig. 7. For the X-port, the surface current distribution has its maximum value along the x-directed. For the Y-port, the surface current distribution has its maximum value on the $y$-directed. Identical surface current distribution, but with cross-polarization is obtained for both the $\mathrm{X}$ - and $\mathrm{Y}$-ports. The radiation patterns for the $\mathrm{X}$ - and $\mathrm{Y}$ ports at $60 \mathrm{GHz}$ in different planes are shown in Fig. 8. The FBR is $29 / 28 \mathrm{~dB}$ and the co-/cross-polar level of $33 / 33 \mathrm{~dB}$ for the $\mathrm{X}-/ \mathrm{Y}$-port in the $\mathrm{X}-\mathrm{Z}$ plane. The FBR is $30 / 29 \mathrm{~dB}$ and the co-/cross-polar level of $34 / 32 \mathrm{~dB}$ for the $\mathrm{X}-/ \mathrm{Y}$-port in the $y-z$ plane. In order to investigate the effect of the CMOS six-metal layers structure on the radiation characteristics of the on-chip antenna, the metal layers are inserted with the dual-polarized antenna as shown in Fig. 9a. The six-metal layers are surrounding the patch to investigate its effect on the antenna radiation characteristics. The variation of the reflection coefficient versus frequency for the dualpolarized antenna is shown in Fig.9b. A slight shift in the resonance frequency of about $0.5 \mathrm{GHz}$ with nearly the same matching bandwidth due to the presence of the six-metal layers. This shift can mainly take into account during the antenna design by adjusting the patch dimensions. 


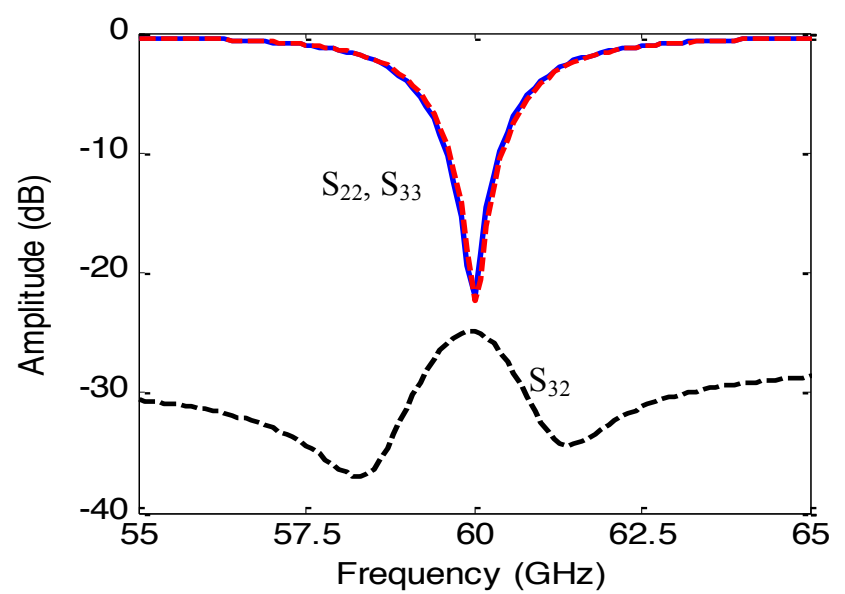

a. S-parameters

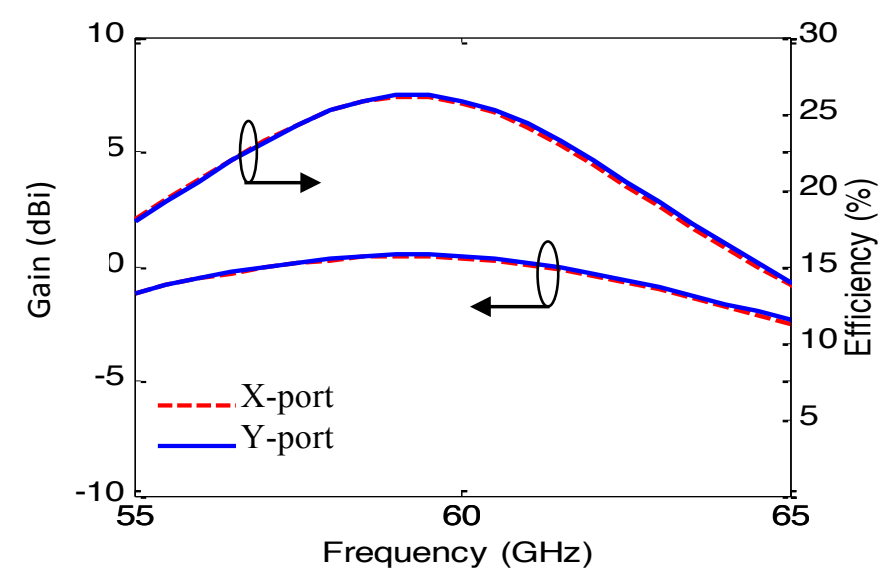

b. Gain and efficiency

Fig.6 a. The variation of the S-parameters versus frequency for the dual-polarized microstrip patch on-chip antenna. $b$. The variation of gain and radiation efficiency versus frequency for the dual-polarized microstrip patch on-chip antenna.
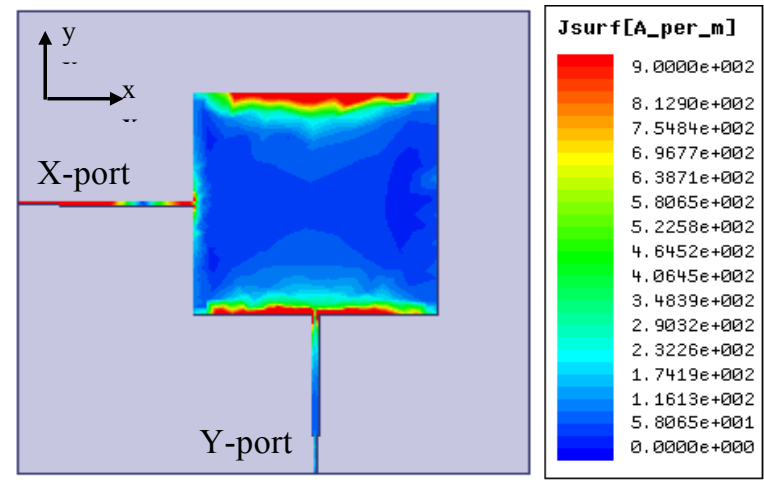

a. X-port excitation
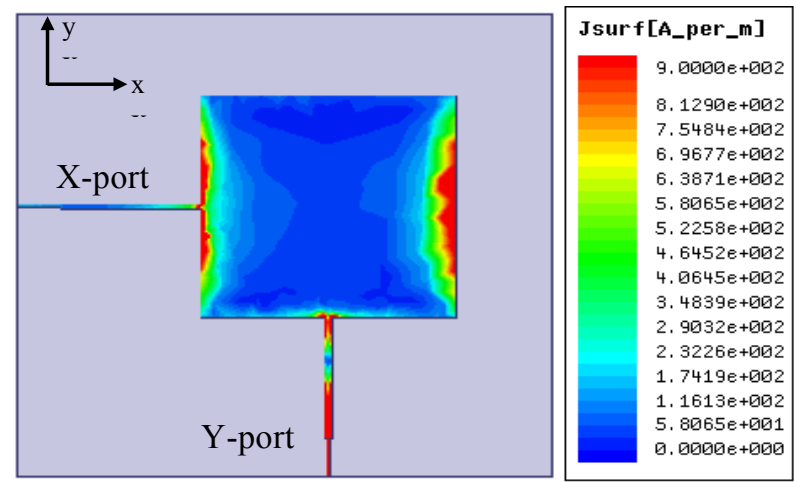

b. Y-port excitation

Fig. 7. The surface current distribution on the dualpolarized microstrip patch on-chip antenna for both the Xport and Y-port at $60 \mathrm{GHz}$.

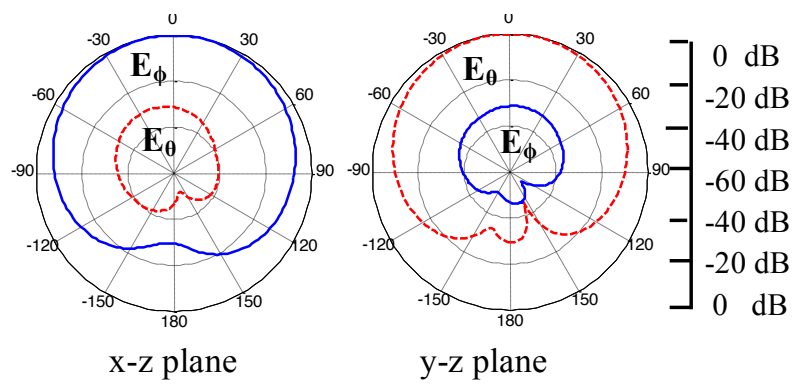

a. X-port excitation

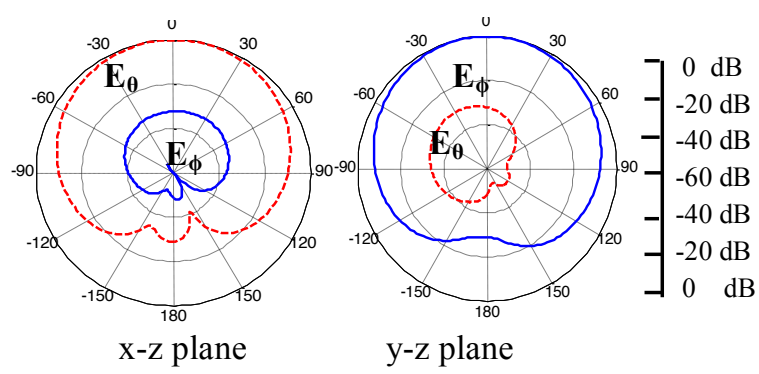

b. Y-port excitation.

Fig. 8. The radiation patterns of the dual-polarized microstrip patch on-chip antenna for both the X-port and Yport at $60 \mathrm{GHz}$ in different planes.

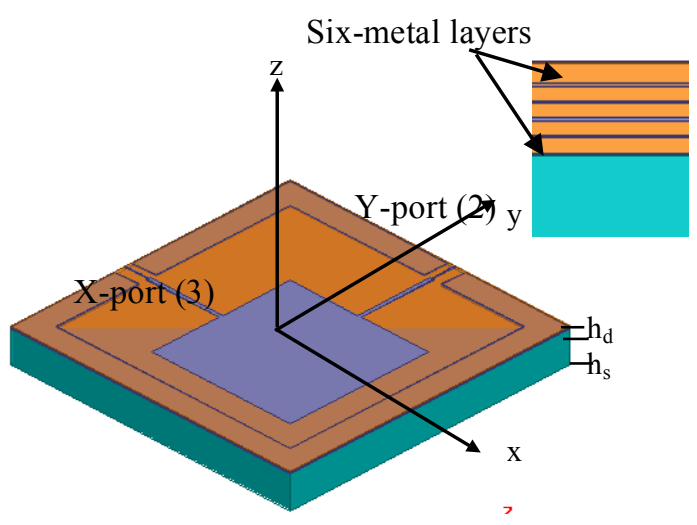

a. 3-D geometry 


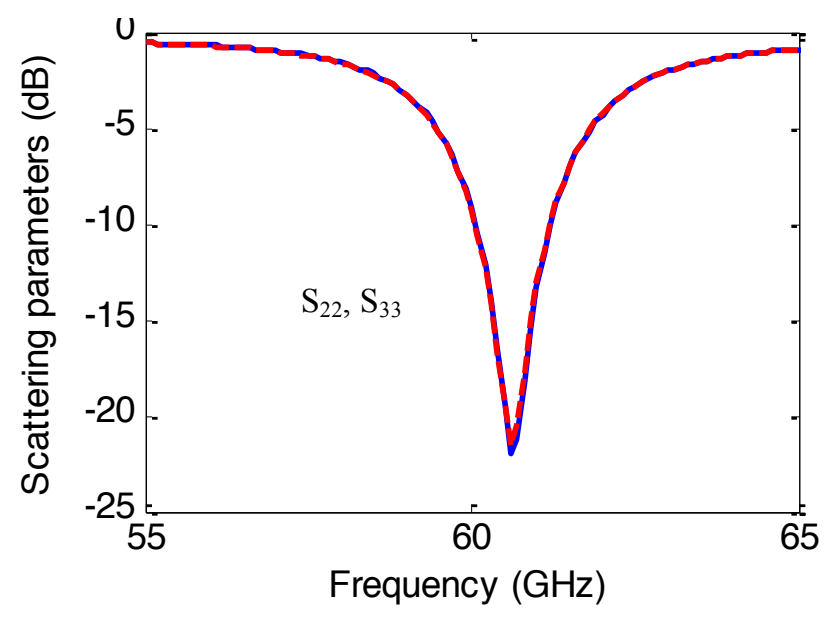

b. S-parameters

Fig.9 a. The geometry of the dual-polarized microstrip onchip patch antenna with six-metal layers. $b$. The variation of the S-parameters versus frequency for the dual-polarized microstrip patch on-chip antenna in the presence of the sixmetal layers.

\subsection{Circular polarized and dual polarized antennas on the same chip:}

For multi-chip wireless communications, both the CPmicrostrip and dual-polarized microstrip patch on-chip antennas are placed face-to-face with a separation distance $\mathrm{D}$ between their edges, as shown in Fig. 10a. The CPmicrostrip patch on-chip antenna is applied as a transmitting antenna and the dual-polarized microstrip patch on-chip antenna is applied as a receiving antenna. The power transmission gain ( $\mathrm{Gi}$ ) between the transmitting and the receiving antenna, is defined by

$$
G_{i}=\frac{\left|S_{i 1}\right|^{2}}{\left(1-\left|S_{11}\right|^{2}\right)\left(1-\left|S_{i i}\right|^{2}\right)} \quad, i=2,3
$$

Due to the high isolation between the $\mathrm{X}$ - and $\mathrm{Y}$-port of the dual-polarized antenna, the two ports can be considered as a two separate receiving antennas. The CP-microstrip patch on-chip antenna is considered as a transmitting antenna and each port of the dual-polarized antenna is considered as a receiving antenna.

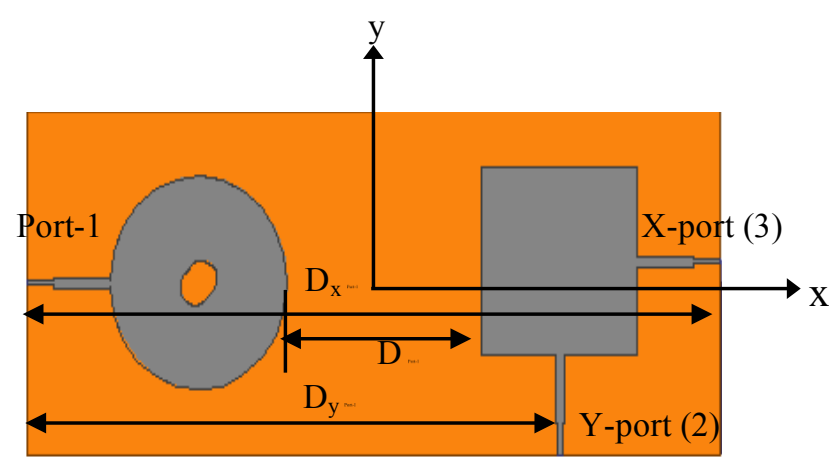

a. 2-D view

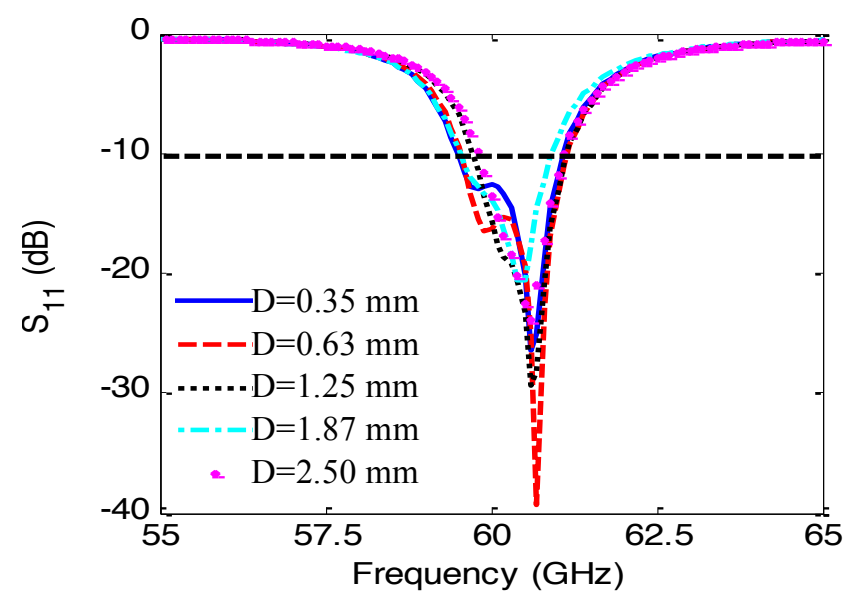

b. Reflection coefficient (dB)

Fig. 10a. The detailed arrangement of the CP microstrip and the dual-polarized microstrip patch on-chip antenna with separation distance D. b. The variation of the reflection coefficient of the CP-microstrip patch on-chip antenna in the presence of the dual- polarized on-chip antenna versus frequency for different separation distance D.

The variations of the reflection coefficient of the $\mathrm{CP}$ microstrip patch on-chip antenna in the presence of the dual-polarized antenna versus frequency for different separation distance D are shown in Fig. 10b. The impedance matching bandwidth is varied between $2 \mathrm{GHz}$ for $\mathrm{D}=0.5$ $\mathrm{mm}$ and $2.4 \mathrm{GHz}$ for $\mathrm{D}=2.5 \mathrm{~mm}$ with nearly the same resonant frequency. The variations of the transmission coefficient between the CP-microstrip patch on-chip antenna (port-1), X-port (3) and Y-port (2) versus frequency for different separation distance $\mathrm{D}$ are shown in Fig. 11. For the each separation distance $D_{x}\left(D_{x}=D+3.8 \mathrm{~mm}\right)$ and $D_{y}$ $\left(D_{y}=D+2.6 \mathrm{~mm}\right)$, the transmission coefficient has its maximum value near the resonance frequency of the antennas for both $\mathrm{X}$-and Y-port. As the distance increased the transmission coefficient decreased due to the broadside radiation of the $\mathrm{X}$ - and $\mathrm{Y}$ - port. For $\mathrm{D}=1.5 \mathrm{~mm}$ the transmission coefficient is $-32 \mathrm{~dB}$ for the $\mathrm{X}$-port and $-35 \mathrm{~dB}$ for the Y-port.

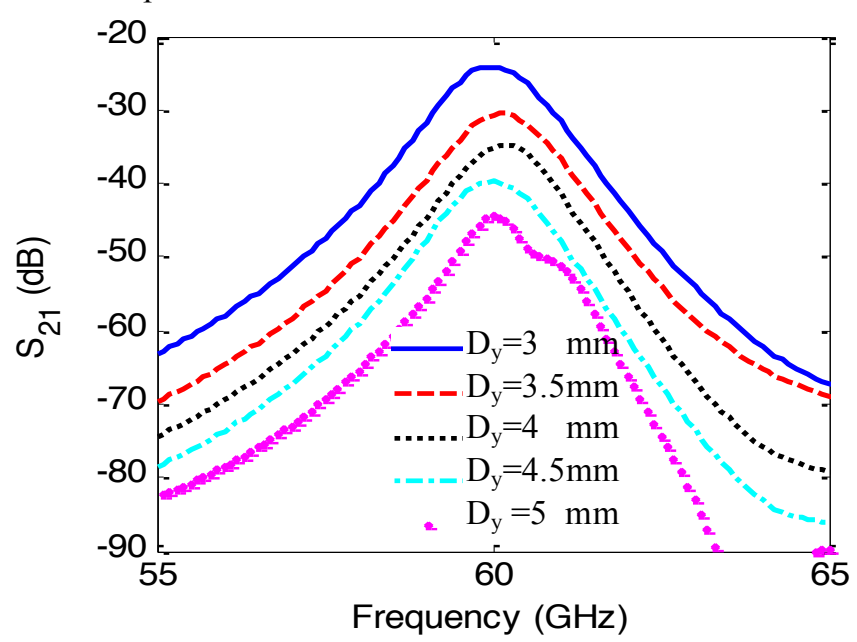


a. Transmission coefficient (S21)

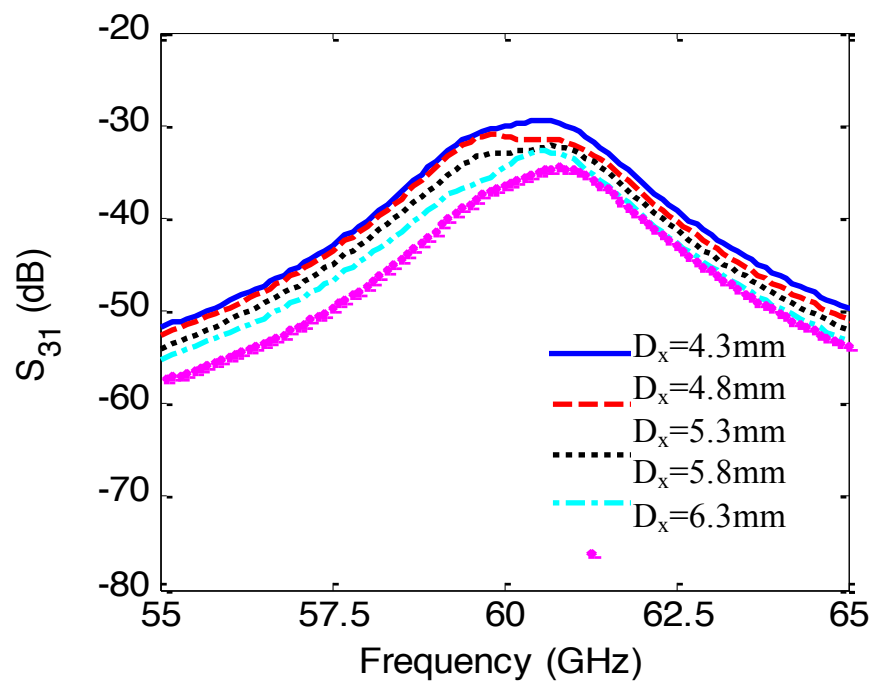

b. Transmission coefficient (S31)

Fig. 11. The transmission coefficient between the CPmicrostrip patch on-chip antenna (port 1) and the dualpolarized microstrip patch on-chip antenna (Y-port (2) and $\mathrm{X}$-port (3)) versus frequency for different separation distance D.

The variation of the transmission gain between the two antennas versus frequency at different separation distance D for the X-and Y-port is shown in Fig. 12a. For both the Xand Y-port, the transmission gain is decreased with increasing the separation distance between the antennas as shown in Fig. 12b. The transmission gain and transmission coefficient decreasing rate for the Y-port is faster than that for the $\mathrm{X}$-port due to their positions relative to the $\mathrm{CP}$ antenna. The transmission gain varies from $-23.5 \mathrm{~dB}$ to -43 $\mathrm{dB}$ for the Y-port while it varies from $-29.5 \mathrm{~dB}$ to $-35.5 \mathrm{~dB}$ for the $\mathrm{X}$-port. The radiation efficiency variation versus separation distance at $60 \mathrm{GHz}$ is nearly the same of about $25 \%$ dominate for both ports at different separation distances.

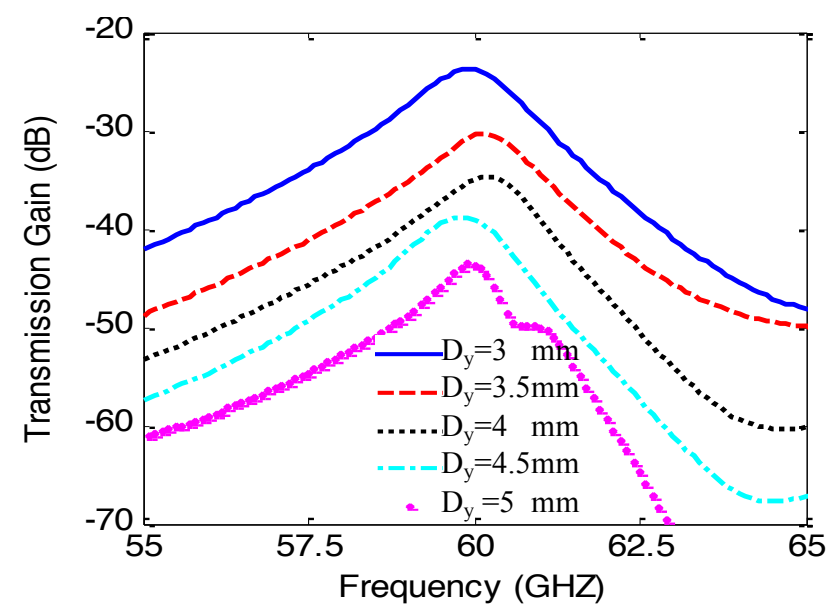

a. Transmission gain versus frequency

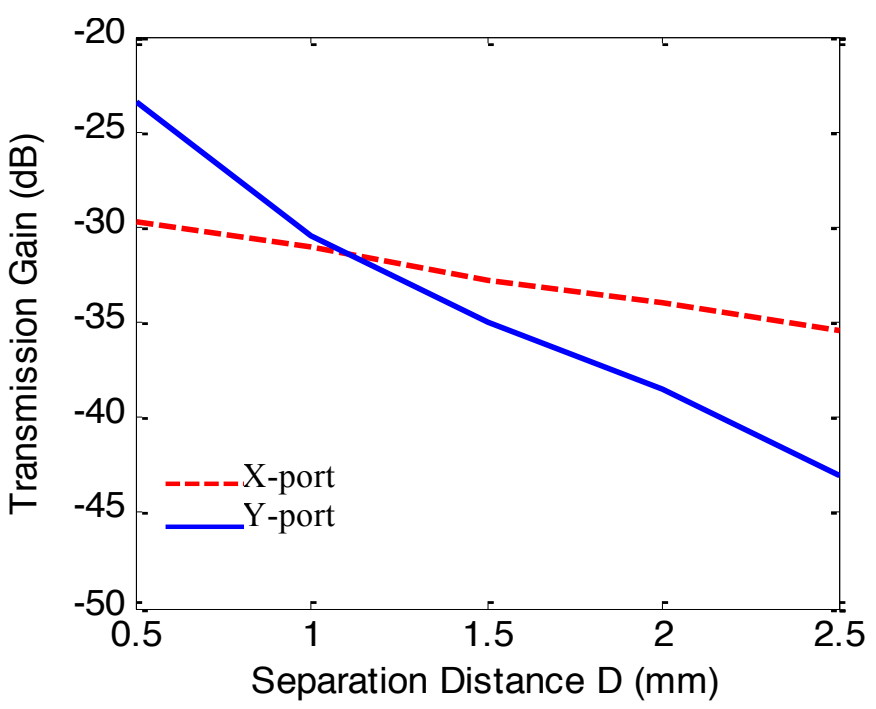

b. Transmission gain versus distance

Fig. 12. The transmission gain versus frequency and the transmission gain versus separation distance between the CP-microstrip on-chip antenna (port 1) and the dualpolarized on-chip antenna (Y-port (2) and X-port (3)) versus separation distance $\mathrm{D}$ at $60 \mathrm{GHz}$.

\section{CONCLUSION}

The paper introduces two different designs for on-chip microstrip antennas for wireless data transmission at 60 $\mathrm{GHz}$ applications. The first proposed design is a circularly polarized circular microstrip patch on-chip antenna with two overlapped circular slots fed by microstrip transmission line using the $0.18 \mu \mathrm{m}$ CMOS technology. The antenna introduces an impedance matching bandwidth of $2.85 \mathrm{GHz}$ centered at $60 \mathrm{GHz}$. The antenna gives left-hand circular polarization with axial ratio bandwidth of $600 \mathrm{MHz}(6 \%)$. Maximum gain of $0.3 \mathrm{~dB}$ and radiation efficiency of $25 \%$ at $60 \mathrm{GHz}$ are obtained. The second proposed on-chip antenna is a dual-port square patch with dual feeding transmission lines at two orthogonal edges of the patch for $60 \mathrm{GHz}$ applications. Good isolation between the two ports is obtained (about $-25.4 \mathrm{~dB}$ at $60 \mathrm{GHz}$ ). Both the X-port and $\mathrm{Y}$-port introduces a maximum gain of $0.7 \mathrm{~dB}$ and radiation efficiency of $25 \%$ at $60 \mathrm{GHz}$ due to the symmetry in the antenna configuration. The CP-microstrip patch on-chip antenna is considered as a transmitting antenna and each port of the dual-polarized antenna is considered as a receiving antenna. The impedance matching bandwidth is varied between $2 \mathrm{GHz}$ for $\mathrm{D}=0.5 \mathrm{~mm}$ and $2.4 \mathrm{GHz}$ for $\mathrm{D}=1$ $\mathrm{mm}$ with nearly the same resonant frequency. As the distance is increased the transmission coefficients between the CP-microstrip on-chip antenna (port-1) and the X-(port3 ) and Y-(port-2) ports are decreased. 


\section{REFERENCES}

[1] S.S. Hsu, K.C. Wei, C.Y. Hsu, and H.R. Chuang, “A 60-GHz Millimeter-Wave CPW-Fed Yagi Antenna Fabricated by Using 0.18- $\mu \mathrm{m}$ CMOS Technology," IEEE Electron Device Letters, vol. 29, no. 6,pp. 625627, June 2008.

[2] R.C. Daniels, J.N. Murdock, T.S. Rappaport, and R. W. Heath, " $60 \mathrm{GHz}$ wireless: up close and personal, 'IEEE Microwave Magazine, vol. 11, no. 7, pp. 44-50, December 2010.

[3] C.H. Doan, S. Emami, D.A. Sobel, A.M. Niknejad, and R.W. Brodersen, "Design considerations for $60 \mathrm{GHz}$ CMOS radios," IEEE Communications Magazine, vol. 42, no. 12, pp. 132-140, December 2004.

[4] J. Wells, "Faster than fiber: the future of multi-G/s wireless," IEEE Microwave Magazine, vol. 10, no. 3, pp. 104-112, May 2009.

[5] K. Kim, H. Yoon, and K.O. Kenneth, "On-chip wireless interconnection with integrated antennas, " IEDM Tech. Dig., pp. 485-488, San Francisco, USA, December 2000.

[6] Y.P. Zhang, M. Sun, and L.H. Guo, “ On-chip antennas for 60-GHz radios in silicon technology," IEEE Trans. on Electron Devices, vol. 52, no. 7, pp. 1664-1668, July 2005.

[7] T. Hirano, K. Okada, J. Hirokawa, and M. Ando," 60 $\mathrm{GHz}$ on-chip patch antenna integrated in $0.18-\mu \mathrm{m}$ CMOS Technology," Proceeding of International Symposium on Antennas and Propagation (ISAP), Paper ID 1B4-2, pp. 62-65, Nagoys, Japan, November 2012.

[8] F. Touati and M. Pons, "On-chip integration of dipole and VCO using standard BiCMOS technology for 10 $\mathrm{GHz}$ applications," European Solid-State Circuits Conference, pp. 494-496, Estoril, Portugal, October 2003.

[9] P.V. Bijumon, A.P. Freundorfer, and Y.M.M. Antar, "Integrated dielectric resonator antennas on conductive silicon substrate for millimeter wave applications", Proc. of Antennas and Propagation Symposium, pp. 179 - 182, Kochi, India, 2006.

[10]M. Pons, F. Touati and P. Senn, "Study of on-chip integrated antennas using standard silicon technology for short distance communication", Proc. of the Eur. Conf. on Wireless Technology, pp. 273-276, Paris, 2005.

[11]A. Fonte, S. Saponara, G. Pinto, and B. Neri, "Feasibility study and on-chip antenna for fully integrated $\mu$ RFID tag at $60 \mathrm{GHz}$ in $65 \mathrm{~nm}$ CMOS SOI," IEEE International Conference on RFID-Technologies and Applications, pp. 449-454, Sitges, 2011.

[12] J.P. Carmo, P.M. Mendes, C. Couto, and J.H. Correia, "5.7 GHz on-chip antenna/RF CMOS transceiver for wireless sensor networks," Elsevier B.V. Sensors and Actuators, vol. 132, no. 1, pp. 47-51, November 2006.
[13] A. Triantafyllou, A. Farcy, P. Benech, F. Ndagijimana, O. Exshaw, C. Tinella, O. Richard, Ch. Raynaud, and J. Torres, " Intra-chip wireless interconnections based on high performances integrated antennas," Elsevier Ltd. Solid-State Electronics 49, vol. 49, no. 9, pp. 14771483, September 2005.

[14] X.Y. Bao, Y.X. Guo, and Y.Z. Xiong, "60-GHz AMCbased circularly polarized on-chip antenna using standard $0.18-\mu \mathrm{m}$ CMOS technology," IEEE Trans. On, Antennas and Propagation, vol. 60, no. 5, pp. 22342241, May 2012.

[15] CST microwave studio, www.CST.com.

[16]High Frequency Software Simulator (HFSS). ver. 13.02, Ansoft Corporation, Canonsburg, $P A$.

[17]R. Garg, Microstrip antenna design handbook, Artech house, 2001.

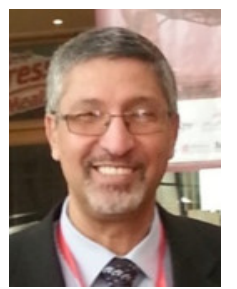

Saber Helmy Zainud-Deen: was born in Menouf, Egypt, on November 15, 1955. He received the B.Sc. and M.Sc. degrees from Menoufia University in 1973 and 1982, respectively, and the Ph.D. degree in Antenna Engineering from Menoufia University, Egypt in 1988. He is currently a Professor in the Department of Electrical and Electronic Engineering in the Faculty of Electronic Engineering, Menoufia University, Egypt. His research interest at present include microstrip and leaky wave antennas, DRA, RFID, optimization techniques, FDFD and FDTD, scattering problems and breast cancer detection.

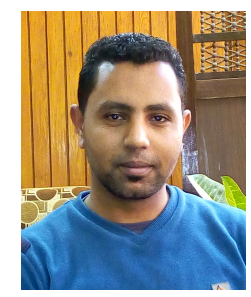

Saied Abd Elhamied: was born in Menouf, Egypt, on July 1, 1991. He received the B.Sc. degree from Menoufia University in 2013. He is currently an Teaching Assistant in the Department of Electrical and Electronic Engineering in the Faculty of Electronic Engineering, Menoufia University, Egypt. $\mathrm{He}$ is currently working toward her M.Sc. degree in Antenna Engineering from Menoufia University. His research interest at present include on-chip antennas, DRA, transmitarray, and reflectarray.

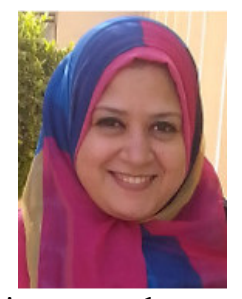

Hend Abd El-Azem Malhat: was born in Menouf, Egypt, on December 12, 1982. She received the B.Sc. and M.Sc. degrees from Menoufia University in 2004 and 2007, respectively. She received her Ph.D. degree in Antenna Engineering from Menoufia University, Egypt in 2011. She is currently an Associat Professor in the Department of Electrical and Electronic Engineering in the Faculty of Electronic Engineering, Menoufia University, Egypt. Her research interest at present includes graphene antennas, plasma antennas, wavelet techniques, transmitarray, reflectarray and RFID. 